\title{
Determination of External and Internal Mixing of Organic and Inorganic Aerosol Components from Hygroscopic Properties of Submicrometer Particles During a Field Study in the Lower Fraser Valley
}

\author{
Yayne-Abeba Aklilu and Michael Mozurkewich \\ Department of Earth and Space Science and Centre for Atmospheric Chemistry, York University, \\ Toronto, Ontario, Canada
}

\begin{abstract}
A tandem differential mobility analyzer (TDMA) system was developed to measure particle growth factors over a range of relative humidities from $50-85 \%$. This system was deployed in the Lower Fraser Valley, and data was collected at Golden Ears Provincial Park and Eagle Ridge Mountain during the Pacific 2001 field study. Following humidification, particles either had a single hygroscopic mode or a bimodal distribution with more hygroscopic and less hygroscopic modes. Growth factors for the less hygroscopic mode were found to be consistent throughout the study. Monomodal distributions were the more common result. Their growth factor ranged between that of the less and the more hygroscopic modes. Using observed and calculated growth factors, relative organic and inorganic fractions were estimated. Particles at these sites were largely organic. Organic fractions near unity were found at Golden Ears forest and during rainy days at Eagle Ridge.
\end{abstract}

\section{INTRODUCTION}

The atmospheric aerosol is a very complex system; individual particles contain a large number of chemical constituents and the composition may vary with particle size, from one particle to another, and from one place or time to another. The simplest classification of the chemical compounds in a particle is as organic or inorganic. For submicrometer particles, the latter (other than water) are overwhelmingly anthropogenic, except in parts of the atmosphere that are remote from human activity. Organic

This work was supported by grants from the Natural Sciences and Engineering Research Council and the Canadian Foundation for Climate and Atmospheric Science. We thank the Greater Vancouver Regional District for providing meteorological data.

Address correspondence to Michael Mozurkewich, Department of Earth and Space Science and Centre for Atmospheric Chemistry, York University, 4700 Keele Street, Toronto, Ontario M3J 1P3, Canada. E-mail: mozurkew@yorku.ca compounds may be of either anthropogenic or biogenic origin. Some of the aerosol components are nonvolatile and are confined to the particle phase; others are semivolatile and may partition to varying degrees between the particle and gas phases. In terms of mass, the most important of these semivolatile components is water. We refer to the ability of particles to gain and lose water with changes in relative humidity as their hygroscopic properties. The measurements reported here are designed to better understand these hygroscopic properties of atmospheric particles and to explore the extent to which the atmospheric aerosol is internally mixed (all particles with the same composition) or externally mixed (composition varies from one particle to another).

The hygroscopic properties of aerosol particles are fundamental to their effectiveness as cloud condensation nuclei, their atmospheric residence times, their influence on global radiation balance, and their chemical reactivity. The hygroscopic behavior of a particle is controlled by its chemical composition; inorganic compounds generally have a much greater tendency to absorb water than organic compounds. Hygroscopic measurements of continental particles often reveal more hygroscopic and less hygroscopic modes, although some measurements of urban particles have shown as many as six modes (Cocker et al. 2001). Oftentimes the less hygroscopic mode only takes up a very small amount of water, while the water uptake of the more hygroscopic mode is less than expected for pure inorganic salt particles. In the past, these particles have been supposed to be composed of a soluble, hygroscopic portion (inorganic salt) and an insoluble, nonhygroscopic portion (organic compound) (e.g., Pitchford and McMurry 1994).

The hygroscopic properties of inorganic compounds common to the atmosphere have been extensively studied (Tang and Munkelwitz 1994; Tang 1997; Ha et al. 2000). Recent findings have shown that classifying the organic portion as insoluble may be inadequate. Laboratory studies on mixed particles have found that while adding organic material may reduce the hygroscopic 
growth of an inorganic particle, water absorption is not solely due to the inorganic portion of the particle (Cruz and Pandis 2000; Virkkula et al. 1999). At high relative humidity the volume uptake of water due to the organic fraction may be smaller than the inorganic fraction; however, at lower relative humidity the organic fraction may enhance water uptake (Dick et al. 2000). The organic component of the atmospheric aerosol can be roughly categorized into two major groups: water soluble and insoluble. Peng et al. (2001) found that some organic particles such as succinic and oxalic acids show no growth even at a relative humidity of $94 \%$ while others such as malonic citric, malic, and tartaric acid absorb substantial amounts of water.

An important factor in the hygroscopicity of atmospheric particles is the interaction of the inorganic and organic components. Studying the hygroscopicity of mixed particles of ammonium sulphate and oxidation products of biogenic organics, Virkkula et al. (1999) found that the water uptake of a mixed particle could be estimated from the water uptake of its individual components. Knowing the growth factors of the pure organic and inorganic components, the relative organic or inorganic fraction of particles may be calculated from their growth factors.

The leading method for studying the hygroscopic properties of ambient particles has been the tandem differential mobility analyzer (TDMA) method. The general procedure is to dry the ambient aerosol particles, use a differential mobility analyzer (DMA) to select a monodisperse fraction, humidify the monodisperse particles, and then use a second DMA with a condensation nucleus counter (CNC) as a detector to measure the size distribution of the humidified particles. Typically, samples are humidified to a relative humidity in the range of $80-90 \%$. Sampling at a number of relative humidities is often not done because this may jeopardize time resolution of the data, as stabilizing the equipment to selected relative humidities can be time consuming.

In the system described here, the relative humidity was scanned at a rate that was slow enough to produce only a small change during one sample period yet fast enough to obtain a reasonable time resolution. The sheath flows were recirculated to reduce the amount of heating required to reach high relative humidities. This TDMA system was used to investigate the hygroscopicity of atmospheric particles during the multiinvestigator Pacific 2001 field study in the lower Fraser Valley in British Columbia, Canada. Samples were taken at a forested site and at a mixed anthropogenic-biogenic site during the month of August. The chosen dry particle sizes were 50, 80, 114, and $160 \mathrm{~nm}$. Not all of the sizes were sampled for the entire sample period. Hygroscopicity of particles was examined at relative humidities ranging from $50-85 \%$.

\section{INSTRUMENTATION AND DATA REDUCTION}

\section{Experimental Setup}

A schematic diagram of our TDMA system is shown in Figure 1. The unique features of this system were that it allows the relative humidity to be scanned. Also, instead of the conventional method of using two CNCs, just one $\mathrm{CNC}$ was used since we only had one available. In order to minimize interruptions in sampling, efficient drying and humidification systems that do not require extensive maintenance were needed.

A stirred volume was placed upstream of the TDMA system; this was done to average out particle concentration variation over time. A flow of about 3.2 actual liters per minute (alpm) was drawn through a 3 liter round-bottom flask that was slowly stirred in order to produce mixing without excessive particle loss. A multitube nafion dryer (Perma Pure model PD-625-24SS) was used to dry the sample flow to an average relative humidity of $15 \%$. A portion of the flow exiting the drier (about $2.0 \mathrm{alpm}$ ) was used as the drier purge flow, which flowed countercurrent in the outer shell of the drier. The nafion membrane allowed the diffusion of water vapor but not other gases; this was assisted by reducing the purge flow pressure to about $25 \mathrm{kPa}$. Laboratory tests showed that less than $5 \%$ particle loss occurred in the nafion drier. This would not have interfered with our measurements provided that the loss was not composition dependent.

The dried sample flow (1.2 alpm) then passed through a ${ }^{210}$ Po bipolar charger before entering the first DMA (DMA1; TSI model 3071), where monodisperse particles were selected. The DMA sizes charged particles according to their electrical mobility (Knutson and Whitby 1975). All particles exiting the DMA with a given charge have very nearly the same size; we assume here that all particles were singly charged. A small fraction of particles with more than one charge would have been larger than the size calculated by assuming a single charge. The sheath flow for DMA1 (10.5 alpm) was recirculated using a mass flow controller (MKS model 1259C) and a diaphragm pump (Gast model DOA-P10A-AA); this was similar to the setup of Jokinen and Mäkelä (1997). Recirculation of the sheath flow allowed the relative humidity in the first DMA to equilibrate to that of the sample flow. The relative humidity and temperatures of the sheath flows for the two DMAs were recorded at the excess air outlets using Vaisala Humitter $50 \mathrm{Y}$ sensors. These were calibrated against an EG\&G dew point sensor (model $911 \mathrm{DEW}$ ALL); the scatter in these calibrations indicated that the sensors have a precision of $0.8 \%$.

A portion $(0.3 \mathrm{alpm})$ of the monodisperse aerosol flow from DMA1 was sent directly to the CNC (TSI model 7610). The remainder (1.0 alpm) entered another nafion drier (Perma Pure model MD-110-24F) in which the recirculating humidified sheath flow for DMA2 was used as a cocurrent purge flow. This system ensured that the aerosol and sheath flows had the same humidity in DMA2 and will be referred to as the humidifier. The relative humidity of the two flows was measured in the laboratory to make sure that they had equilibrated; the difference between them was less than $2 \%$. To determine that particles were given enough time to grow, experiments were run using various inorganic salts, and their growth factor was compared to calculated growth factors. Excellent agreement was obtained; an example is shown in Figure 2. 


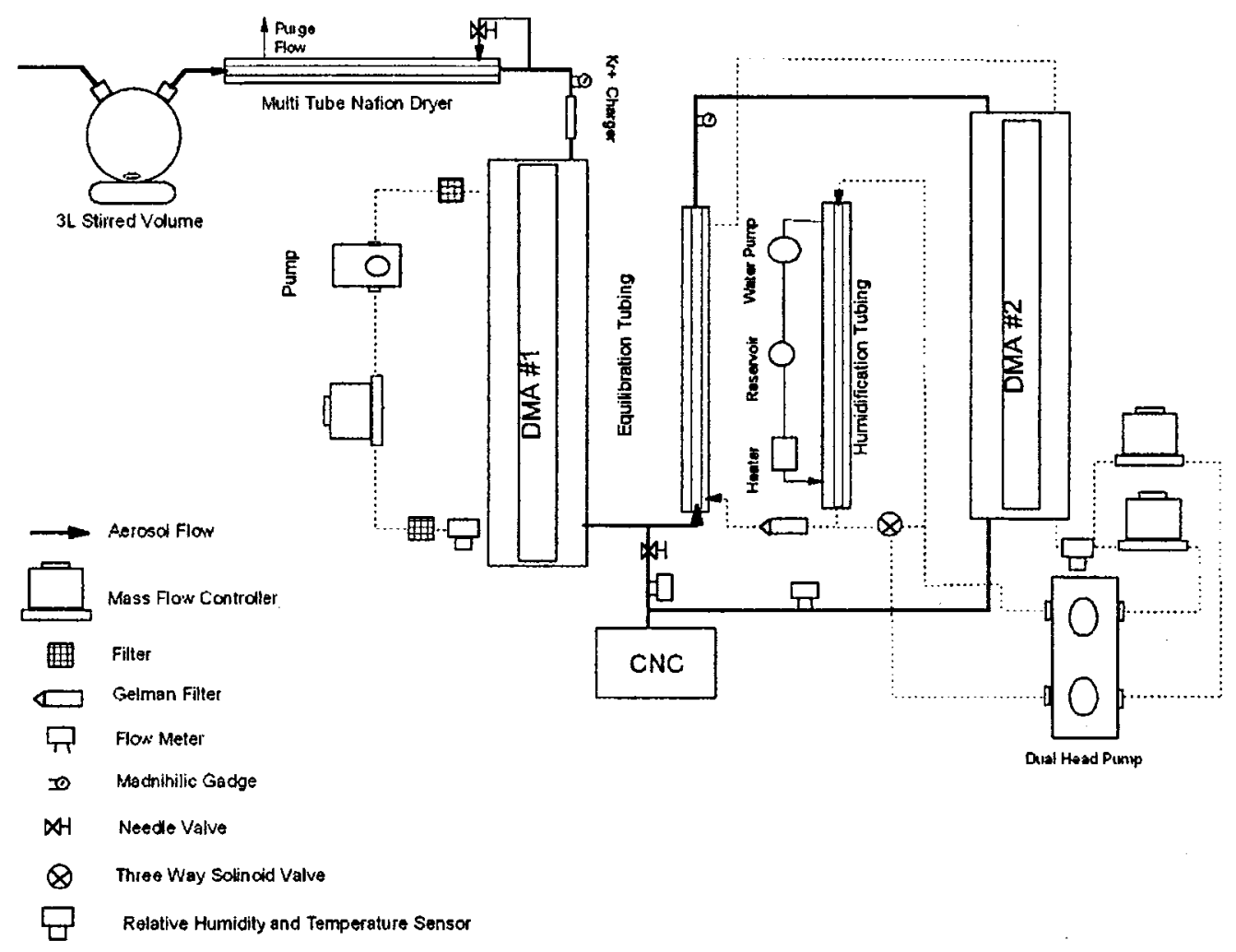

Figure 1. The tandem differential mobility analyzer system.

After leaving the humidifier, the aerosol flow entered the second DMA; this was used to measure the final particle size after humidification. To control the relative humidity, the sheath flow (10.5 alpm) exiting DMA2 was divided into two flows $(0.5$ and 10.5 alpm) using two mass flow controllers and a dual-headed di-

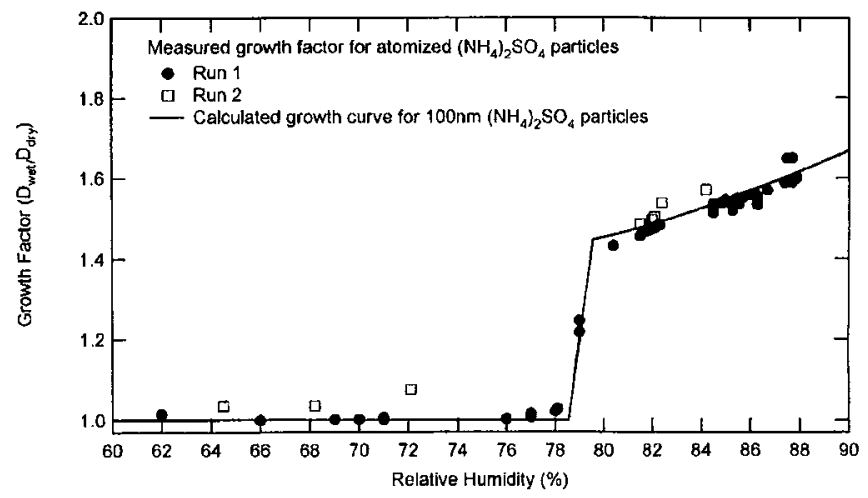

Figure 2. Comparison of calculated growth factor for ammonium sulphate particles with growth factor as measured by the TDMA. Uncertainties in the growth factors are based on counting statistics and may be underestimated since they do not include uncertainties in the flows and relative humidity; therefore, error bars shown are $3 \%$ of the measured growth factor. aphragm pump (Gast model DAA-V174-EB). The smaller portion of the flow was always passed through the saturator, which consisted of a nafion humidifier (Perma Pure model MH-07024P) in which distilled water was circulated as the purge flow. A three-way solenoid valve was used to alternately pass the larger portion either through or around the saturator to change the humidity; this is described in more detail below.

The monodisperse aerosol flow from DMA2 was combined with a portion of the flow from DMA1 and sent to the CNC. A computerized data acquisition system was used to record the pulses from the CNC and to control the voltages on the DMAs. The concentration of particles exiting DMA 1 was measured by setting the voltage on DMA2 to zero before and after each scan; the separation of counts from the two DMAs is described in more detail below.

The aerosol flows into the two DMAs were measured using the pressure drop across laminar flow elements and monitored using Magnehilic gauges (Dwyer Series 2000-0 C). Readings of these gauges were taken every hour during the day; they were not found to vary significantly. Daily averages of these readings were used when processing data. The more critical aerosol flows from the DMAs to the CNC were measured using laminar flow elements, monitored using differential pressure transducers (Omega XP277 and MKS 223B), and recorded with the computer data acquisition system; the average over each sample period was used when processing data. 
Mass flow controllers were used to control the sheath flows, but volumetric flows should be used in calculating particle size. Since the ambient temperature and pressure vary and since the calibration of the mass flow controllers was done at a different altitude to the sample site, the sheath flows may be in error by a few percent. However, the results involve a comparison of particle size at the first and second DMA and the sheath flows in both DMAs will be affected in the same manner; thus, the use of mass flow controllers is not expected to affect the results. The mass flow controllers were calibrated using a bubble flow meter (Gilian Gilibrator).

For daytime sampling, DMAl was set to alternately select 50 and $114 \mathrm{~nm}$ diameter particles. For the later part of the study (27-31 August 2001), the $50 \mathrm{~nm}$ particle concentrations were low during the night. The resulting poor counting statistics introduced large uncertainties when fitting DMA2 distributions; therefore DMA1 for this period (mostly at night) was set to select 110 and $160 \mathrm{~nm}$ particles instead. Each full cycle (increase and decrease) of the relative humidity took $2 \mathrm{~h}$.

Humidification System. As mentioned above, the humidifier arrangement allowed us to measure hygroscopic growth at more than one relative humidity by varying the humidity at the second DMA. Different steady-state relative humidities in DMA2 were achieved by changing the fraction of flow that passed through the saturator. Assuming that the initial aerosol flow leaving DMA1 was perfectly dry, mass balance of water vapor leads to the relationship

$$
R H_{D M A 2}=\frac{R H_{s a t} \times Q_{1}}{Q_{1}+Q_{2}}
$$

where $R H_{D M A 2}$ is the relative humidity in DMA2, $R H_{s a t}$ is the relative humidity of flow coming out of the saturator, $Q_{1}$ is the fraction of the sheath flow that passed through the saturator, and $Q_{2}$ is the aerosol flow. Using Equation (1) and assuming $R H_{\text {sat }}$ to be $100 \%$, the alternating flows through the saturator would provide steady-state relative humidities of $33 \%$ and $91 \%$. During the field study the initial aerosol flow relative humidity was about $15 \%$, and $R H_{\text {sat }}$ was less than $100 \%$ when $Q_{1}$ was set to 10.5 alpm. As a result, the steady-state relative humidities obtained were not quite as indicated above. With a flow of $10.5 \mathrm{alpm}$, the maximum relative humidity that could be achieved at the exit of the saturator was about $74 \%$; this was due to evaporation cooling of the water circulating through the saturator. In order to reach the maximum desired relative humidity of $80 \%$ the water reservoir had to be heated $2^{\circ} \mathrm{C}$ above room temperature. The steady-state humidity was affected by the temperature difference between the water reservoir and air temperature inside the trailer in which the instrument was set up in the field. Lower steadystate relative humidities were obtained during hot days when the trailer temperature was higher than the set point temperature of the water reservoir, and the opposite occurred during nights that were colder than anticipated. The water reservoir temperature was often adjusted to counteract this effect.

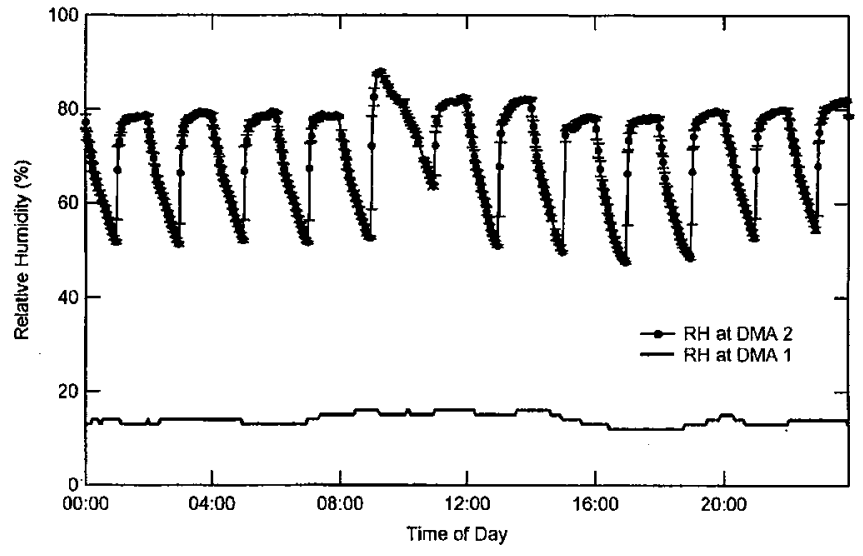

Figure 3. Relative humidity time series of DMA1 and DMA2. Each data point represents a 3.3 min sample period. Error bars indicate the 90 th and 10 th percentile.

Since the DMA2 sheath flow was recirculated, the relative humidity was expected to approach the steady-state relative humidity exponentially with calculated lifetimes (based on volumes) of 3.6 and $19 \mathrm{~s}$ for $Q_{1}$ of 0.5 alpm and 10.5 alpm, respectively; thus, the steady-state relative humidity was expected to be reached in less than $1.5 \mathrm{~min}$. In reality, the humidity increase took somewhat longer and the decrease took much longer; probably due to the absorption and desorption of water onto the filters and Teflon tubing used for the sheath flows. As a result, the lower limit for DMA2 relative humidity was about $50 \%$. A Gelman filter (HEPA capsule 12144) was used for the sheath air of DMA2 and MSA filters (H-95302) were used for the sheath air of DMA1. Figure 3 shows the change in DMA2 relative humidity during one sample day. With the exception of the first two to three scans, the rate of change was slow enough that samples could be taken during the period of humidity decrease; this permitted data to be obtained for a range of humidities. The humidity for each scan was recorded every $2 \mathrm{~s}$, the average, 10 th, and 90th percentiles of these measurements were calculated, and $0.2 \%$ of the scans were rejected because the difference between the 10 th and 90 th percentiles exceeded $3 \%$.

\section{Site Information}

As part of the Pacific 2001 Air Quality Study, data was collected at Golden Ears Provincial Park $\left(49^{\circ} 12^{\prime} 53^{\prime \prime} \mathrm{N} 122^{\circ}\right.$ $\left.34^{\prime} 55^{\prime \prime} \mathrm{W}\right)$ and Eagle Ridge Mountain $\left(49^{\circ} 03^{\prime} 08^{\prime \prime} \mathrm{N} 122^{\circ} 14^{\prime}\right.$ $45^{\prime \prime} \mathrm{W}$ ). Eagle Ridge Mountain is also known as Sumas Mountain. The aim of the study was to investigate ambient particulate matter in the Lower Fraser Valley. Sampling at Golden Ears was done between morning of 7 August and noon of 11 August 2001. The site was located on the northern ridge of the Lower Fraser Valley. The sampling site was located within the park ranger's compound at an elevation of $203 \mathrm{~m}$. The park ranger's compound was in a heavily forested area; activity within the compound was minimal. Foliage in the park is characterized by a second-growth 
forest of Western hemlock, Western red cedar, and Douglas fir. Biogenic emissions were expected to have the greatest influence on particle characteristics at this site. The park occupies an area of over $5.5 \times 10^{8} \mathrm{~m}^{2}$ and contains three campsites; as a result, anthropogenic emissions may contribute to particle characteristics, especially during weekends. Eagle Ridge is located in the Lower Fraser Valley, British Colombia, $75 \mathrm{~km}$ east of the city of Vancouver, and near Abbotsford. The sampling site was located near the top of the mountain at an elevation of $300 \mathrm{~m}$; for the most part the site was expected to be above the nocturnal boundary layer. Sampling at this site took place between 14 August and 31 August, 2001. Particles at Eagle Ridge were expected to be affected by urban, agricultural, and biogenic emissions.

At both locations sample lines consisted of $3 / 4$ inch stainless steel tubing extending to $3 \mathrm{~m}$ above ground level. The sample lines were turned down at the tip to prevent rain water from entering. Instrumentation was located inside an air conditioned trailer. At Golden Ears there was a large amount of instrumentation inside the single trailer; when daytime temperatures reached $30^{\circ} \mathrm{C}$, as frequently happened, the air conditioning system was inadequate and natural ventilation had to be used to cool the trailer.

\section{Data Reduction}

An unusual feature of our TDMA system was that we only had one $\mathrm{CNC}$ available to monitor particle concentrations from both DMAs; this meant that information from the two flows had to somehow be separated. The average total flow into the CNC was 1.34 alpm. About $20 \%$ of the flow was from DMA1 and the remaining flow from DMA2. The voltage on DMA1 was constant during one sample period; therefore particles from DMA1 produced a baseline in the total particles counted by the CNC (see Figure 4). Particles from DMA2 formed a size

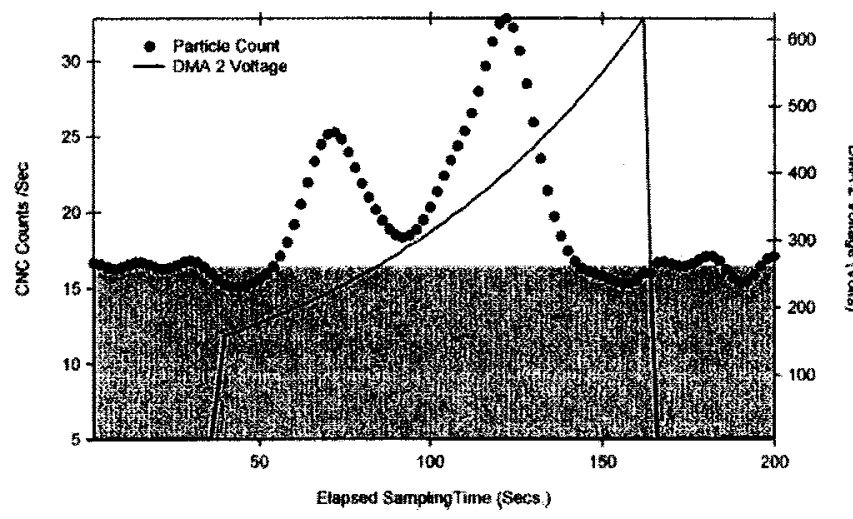

Figure 4. Counting information from the CNC. The baseline count level is the shaded area on the figure, determined from the times when the second DMA was set to zero volts. The humidified size distribution scanned by the second DMA shows two peaks, indicating more and less hygroscopic particles. Also shown is the voltage on the second DMA; the first DMA was set to 200 volts for this sample period. distribution above this baseline. Fluctuations in the baseline were minimized by using a three liter stirred volume at the inlet of the TDMA to average particle concentrations over the sample period. For this technique to work, a CNC with a high flow rate must be used so that the baseline can be subtracted without producing excessive uncertainty from counting statistics.

The voltage on DMA2 was scanned over a sample period of $200 \mathrm{~s}$. For the first $50 \mathrm{~s}$ of the sample period the DMA2 voltage was held at zero, then the DMA2 voltage was ramped up exponentially, and finally the DMA2 voltage was again set to zero for the last $50 \mathrm{~s}$ of the sample period (as shown in Figure 4). The exponential portion of the DMA2 voltage scan began at 0.71 times the voltage on DMA1 and increased with a time constant of $21.7 \mathrm{~s}$. With a continuous exponential scan, the finite time response of the instruments produces an offset in the mobility (Wang and Flagan 1990). The amount of this offset was determined in the laboratory using atomizer-generated particles and was found to be less than $1 \%$ of the voltage; thus no correction for this offset was necessary.

At the start and end of each experiment, when the DMA2 voltage was held at zero, particles counted by the CNC were only from DMA1. The average counting frequencies during these periods were calculated and used to determine the concentration exiting DMA1 and the slope and intercept of the baseline. The baseline was subtracted from the scan, and the variance in the baseline was added to the variance calculated from the counting statistics during the scan.

After subtracting the baseline, the TDMA data were processed using software (TDMAFIT) developed by Stolzenburg and McMurry (1988). This program uses nonlinear least squares fitting to fit the theoretical DMA transfer function to particle concentrations existing in DMA2. The program determines the average diameter growth factor, the diameter spread factor, and the particle fraction at DMA2. The growth factor is the ratio of the mean diameter of particles at DMA2 (humidified) to the diameter exiting DMA1 (dry) and provides a measure of hygroscopicity.

The diameter spread factor provides information on the dispersion in particle size following humidification and is defined by

$$
\begin{aligned}
Z & =\left(\frac{\sigma D_{m p}}{D_{m p}}\right)^{2}-\left(\frac{\sigma D_{t p}}{D_{t p}}\right)^{2}, \\
D F & =s g n|Z|^{1 / 2},
\end{aligned}
$$

where $D F$ is the diameter spread factor, $F D_{m p}$ and $F D_{t p}$ are the measured and theoretical standard deviations, $D_{m p}$ and $D_{t p}$ are the measured and theoretical average diameter, and $s g n$ is the sign of $Z$. A positive value indicates a broadening of the distribution and a negative value a narrowing. The theoretical values were calculated for specific DMA2 conditions (flows, temperature, and pressure). Laboratory experiments done shortly before and after the field study using ammonium sulphate aerosol resulted in an average spread factor of $2 \%$. No difference in the 
dispersion factor was noted for measurements carried out below and above the ammonium sulphate deliquescence point. This value was used to correct results from the field study. In cases when humidification of particles resulted in a multimodal distribution, the program was able to fit a maximum of two modes; the number of distinct modes did not exceed two for this study. A clear separation of externally mixed particles following humidification does not always take pace. Within a single mode, the diameter spread factor may be used to indicate some level of external mixing (McMurry and Stolzenburg 1989). The particle fraction from DMA2 was used in examining particle loss during humidification and in computing the fraction of particles in each mode. Particle loss during humidification was not found to be significant for the sizes sampled; the average fraction exiting DMA2 was found to be $97 \%$ during laboratory measurements and $100 \%$ during the field study.

Uncertainties provided by TDMAFIT are based on the assumption that counting statistics were the only major source of error. The average uncertainty in growth factors due to counting statistics, including the uncertainty in subtracting the baseline, was $\pm 0.6 \%$. Additional sources of error that affected the growth factor were uncertainties in the sheath flow and relative humidity. Average uncertainty in the sheath flows was estimated to be $\pm 0.7 \%$; this was determined from the precision in the mass flow controller calibrations, which were larger than uncertainties from variations in mass flow controller readings. The uncertainty in the relative humidity at DMA2 was due to both relative humidity variation during a scan and uncertainty in sensor calibration. The former was estimated from the 10th and 90th percentiles; the average uncertainty was found to be $\pm 0.5 \%$. The precision of the sensor was found to be much lower than the $\pm 1.5 \%$ accuracy of dewpoint sensor. From the humidity and flow uncertainties, the average uncertainty in determining particle was calculated to be $1.2 \%$. In order to determine uncertainties in particle size from uncertainties in relative humidity, a slope relating growth to relative humidity had to be calculated. This slope was calculated for each sample day for relative humidity above and below $65 \%$. For Golden Ears data, the slope was 0.002 for both relative humidity ranges and sampled sizes. At Eagle ridge, the average slope for data collected below $65 \%$ relative humidity was 0.002 for $50 \mathrm{~nm}$ and 0.006 for $114 \mathrm{~nm}$ particles. Above $65 \%$ relative humidity the average slope was 0.009 and 0.008 for $50 \mathrm{~nm}$ and $114 \mathrm{~nm}$ particles, respectively. Uncertainties in determining particle size, due to delay between DMA2 and the $\mathrm{CNC}$ and due to counting statistics, were propagated to determine the uncertainty in growth factors; the average value was found to be $\pm 1.8 \%$.

Particles with low hygroscopicity were observed to gradually increase in size with increasing relative humidity. A simple, single-parameter function to describe this growth due to the organic fraction can be found in the following way. The water activity of a particle is related to osmotic coefficient by

$$
-\ln \left(a_{w}\right)=\varphi \frac{n_{s}}{n_{w}}
$$

where is $a_{w}$ is the water activity, $n$ is the osmotic coefficient, and $n_{s}$ and $n_{w}$ are the number of moles of solute and water. When the particle is at equilibrium, $a_{w}$ is equal to relative humidity divided by $100 \%$. From the properties of partial molar volumes (Atkins 1994),

$$
\frac{\pi D_{p}^{3}}{6}=V_{s} n_{s}+V_{w} n_{w}
$$

and

$$
\frac{\pi D_{p, o}^{3}}{6}=V_{s} n_{s}
$$

where $D_{p, o}$ is diameter of the dry particle, $D_{p}$ is diameter of the humidified particle, and $V_{s}$ and $V_{w}$ are partial molar volumes of solute and water. We assume that the partial molar volume of the solute is the same in the humidified and dry particles. Using Equations (4)-(6), we eliminate $n_{w}$ and $n_{s}$ to obtain

$$
\frac{D_{p}}{D_{p, o}}=\left(1-\frac{\varphi V_{w}}{V_{s} \ln \left(a_{w}\right)}\right)^{1 / 3} \text {. }
$$

Here $\varphi V_{w} / V_{s}=b$ and is the fitted parameter shown in Figures 5,6, and 7. To apply this equation in fitting the measured growth factors, we must implicitly assume that $\varphi, V_{w}$, and $V_{s}$ do not depend on the composition of the solution. Although this will not in general be true, the effect of variation in these quantities will be a second-order effect in determining the change in size of the particle. Therefore we may assume that these quantities are constant to a first approximation. Assuming that the osmotic coefficient and the solute-to-water density ratio are approximately unity, the value of $b$ will be approximated by the molecular weight ratio of water to solute. We therefore expected $b$ to on the order of 0.1 .

The Kelvin effect creates a small dependence of water activity on particle size; we estimate that between 50 and $114 \mathrm{~nm}$ this

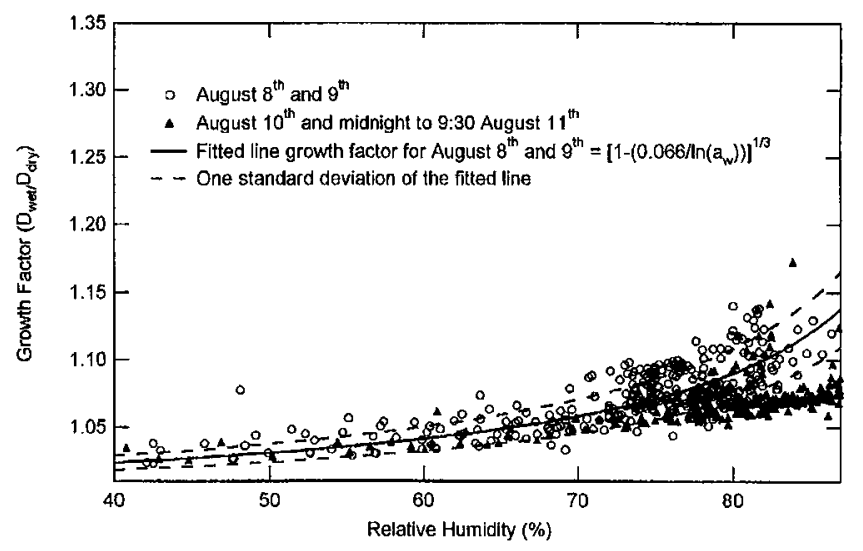

Figure 5. Measured and fitted growth curve for single hygroscopic mode particles at Golden Ears Park for sampling done between 8 and 9 August. 


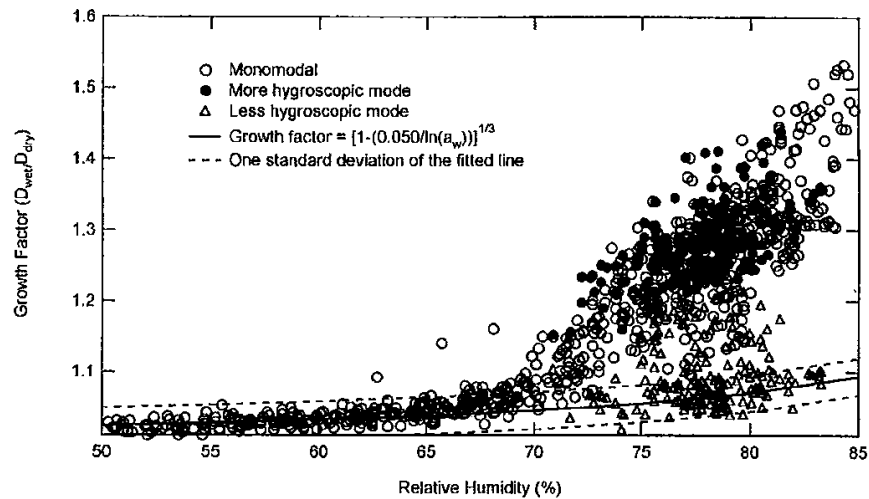

Figure 6. Hygroscopic growth of $114 \mathrm{~nm}$ particles between 14 and 20 August. The fit is to the data for the less hygroscopic mode (circles).

effect changes the growth factor by at most $1.7 \%$ at $85 \%$ relative humidity with smaller changes at lower humidities. Since this change is small and cannot be correctly calculated (since we do not know the surface tension), the Kelvin effect is neglected in this analysis.

\section{RESULTS AND DISCUSSION}

Our technique allows the humidification of particles over a range of relative humidities. In the absence of significant shortterm variability in the particle hygroscopicity, this technique allows the study of growth curves of sampled particles. Humidification of particles resulted in one or two hygroscopic modes. The observation of a bimodal distribution following humidification indicates external mixing. During this study humidification resulted in either a single hygroscopic mode, which will be referred to as monomodal distribution, or a bimodal distribution

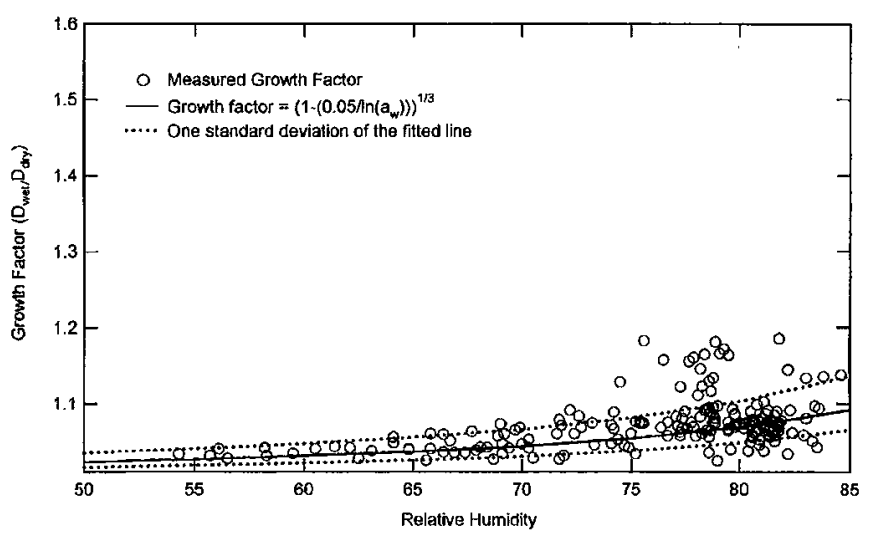

Figure 7. Hygroscopic growth of $114 \mathrm{~nm}$ particles for 22 August the second day of the rain period. Particles on this day had monomodal hygroscopic distributions. The higher growth factors were observed in the late afternoon, when external mixing was noted for the $50 \mathrm{~nm}$ particles. comprised of a more hygroscopic and less hygroscopic mode. The growth factors for the monomodal particles covered the range between the less and more hygroscopic particles. Also, diameter spread factors were used as indicators for varying hygroscopicity of particles within a mode.

\section{Golden Ears}

The aim at Golden Ears was to study the properties of biogenic particles. The extent of biogenic impact on sampled particles can be influenced by the wind direction and therefore fetch over the forested area, anthropogenic activities within the park, and availability of biogenic precursor gases in the area. The emission of biogenic gases that act as precursors to secondary particles, such as monoterpenes, increase with temperature (Derwitt et al. 1998). Sample days at Golden Ears Provincial Park (711 August) were clear and sunny, with daytime temperatures reaching up to $30^{\circ} \mathrm{C}$. As a result, we expected significant biogenic impact on particles sampled.

For the most part, particles at this site had low hygroscopicity. The most hygroscopic particles were found around the times bimodal distributions were also noted, these mainly occurred on 7 and 11 August. Only a few bimodal distributions (less than three consecutive data points) were observed for each of the remaining sample days. Particles on 10 August were found to be the least hygroscopic. Monomodal distributions showed a slight yet noticeable increase in the hygroscopic growth with increase in relative humidity, and no deliquescence behavior was observed. Figure 5 illustrates the relationship between growth factor and relative humidity for particles at this site.

The data at Golden Ears were grouped according to the general hygroscopic trends of the particles. On 7 August, and between 09:30 and 11:00 (all times are Pacific Daylight Time) on 11 August, when the highest growth factors were observed, the parameter $b$ from Equation (7) was $0.103 \pm 0.039$. For clarity, this data was not included in Figure 5. For data collected on 8 and 9 August, $b$ was equal to $0.066 \pm 0.015$; this fit is shown in Figure 5. For 10 August, and between midnight and 09:30 in the morning on 11 August, when the lowest growth factors were observed, the parameter $b$ was $0.039 \pm 0.018$. Chi-squared analysis of the scatter around the fitted line in Figure 5 showed that the observed standard deviation, indicated by the broken lines in Figure 5, was 2.8 times the expected standard deviation due to estimated uncertainties. We therefore conclude that the scatter in the data was due to variation in particle composition.

Growth factors for the monomodal distributions did not show significant differences between sizes (Table 1). Although a slight variability in the hygroscopic property of particles was noted, the average growth factor of $1.07-1.08$ at $80 \pm 1 \%$ relative humidity observed for 8-10 August were similar to reported growth factors of organic particles with low water uptake (Peng et al. 2001) and secondary organic particles from smog chamber experiments (Virkkula et al. 1999). Higher growth factors of 1.13-1.14 for monomodal particles on 7 and 11 August were 
Table 1

Average growth factors for measurements done at relative humidity of $80 \pm 1 \%$, unless otherwise indicated

\begin{tabular}{|c|c|c|c|c|}
\hline \multirow[b]{2}{*}{ Sample period } & \multicolumn{4}{|c|}{ Particle dry diameter } \\
\hline & $50 \mathrm{~nm}$ & $81 \mathrm{~nm}$ & $114 \mathrm{~nm}$ & $160 \mathrm{~nm}$ \\
\hline \multicolumn{5}{|l|}{ Single humidified mode } \\
\hline \multicolumn{5}{|l|}{ Golden Ears } \\
\hline 7 and 11 August $^{a}$ & N/A & $1.13(0.04)$ & $1.14(0.02)$ & N/A \\
\hline 8 and 9 August & N/A & $1.08(0.02)$ & $1.08(0.02)$ & $\mathrm{N} / \mathrm{A}$ \\
\hline 10 and 11 August $^{b}$ & N/A & $1.07(0.01)$ & $1.07(0.02)$ & N/A \\
\hline \multicolumn{5}{|l|}{ Eagle Ridge } \\
\hline 14 and 15 August & $1.25(0.07)$ & N/A & $1.27(0.04)$ & N/A \\
\hline 16-20 August & $1.22(0.09)$ & N/A & $1.29(0.07)$ & N/A \\
\hline $21-23$ August & $1.12(0.05)$ & $\mathrm{N} / \mathrm{A}$ & $1.12(0.06)$ & N/A \\
\hline 24-31 August & $1.13(0.05)$ & N/A & $1.17(0.06)$ & $1.15(0.07)$ \\
\hline \multicolumn{5}{|l|}{ More hygroscopic mode } \\
\hline \multicolumn{5}{|l|}{ Golden Ears } \\
\hline 7-11 August & N/A & N/A & $1.29(0.02)$ & N/A \\
\hline 7-11 August & N/A & $1.28(0.05)^{c}$ & $1.27(0.03)^{c}$ & N/A \\
\hline \multicolumn{5}{|l|}{ Eagle Ridge } \\
\hline 14 and 15 August & $1.26(0: 02)$ & N/A & $1.26(0.03)$ & N/A \\
\hline 16-20 August & $1.34(0.04)$ & N/A & $1.29(0.06)$ & N/A \\
\hline 21-23 August & $1.30(0.06)$ & N/A & $1.28(0.05)$ & N/A \\
\hline 24-31 August & $1.25(0.07)$ & N/A & $1.23(0.05)$ & $1.25(0.03)$ \\
\hline \multicolumn{5}{|l|}{ Less hygroscopic mode } \\
\hline \multicolumn{5}{|l|}{ Golden Ears } \\
\hline 7-11 August & N/A & N/A & $1.11(0.03)$ & N/A \\
\hline 7-11 August & N/A & $1.12(0.02)^{c}$ & $1.10(0.03)^{c}$ & N/A \\
\hline \multicolumn{5}{|l|}{ Eagle Ridge } \\
\hline 14 and 15 August & $1.14(0.03)$ & N/A & $1.12(0.03)$ & N/A \\
\hline 16-20 August & $1.09(0.06)$ & N/A & $1.09(0.04)$ & N/A \\
\hline 21-23 August & $1.09(0.03)$ & N/A & $1.08(0.03)$ & N/A \\
\hline 24-31 August & $1.09(0.05)$ & $1.09(0.05)$ & $1.08(0.04)$ & N/A \\
\hline \multicolumn{5}{|c|}{$\begin{array}{l}\text { On the morning of } 11 \text { August, when these distributions were observed, the re } \\
82 \% \text {. As a result no measurements were done at } 80 \% \text { relative humidity. Therefore } \\
\text { factors values given in Table } 1 \text { had to be estimated for } 80 \% \text { relative humidity us } \\
\text { was applied to the } 114 \mathrm{~nm} \text { particles, it gave good agreement with measurements } \\
{ }^{a} 11 \text { August } 9: 30-12: 00 \text {. } \\
\text { b11 August midnight-9:30 p.m. } \\
\text { 'These values were calculated for } 80 \% \text { relative humidity using Equation (6). } \\
\text { Values shown in parenthesis are standard deviations. }\end{array}$} \\
\hline
\end{tabular}

noted around the time bimodal distributions were observed and may have had an anthropogenic contribution.

A significant amount of external mixing for particles at a forested site was found by Hämeri et al. (2001). Our observations resemble more the hygroscopic behavior of pristine Amazon forest (Zhou et al. 1999). Hygroscopic modes were monomodal; bimodal distributions were sporadic occurrences, comprising $5 \%$ of the measurements performed at relative humidity greater than $75 \%$. However, growth factors observed at Golden Ears were similar to the less hygroscopic particles found by Hämeri et al. (2001). Growth factors for less hygroscopic particles at boreal forest (Hämeri et al. 2001) ranged between 1.12 and 1.17 and between 1.2 and 1.4 for the Amazon; these measurements were preformed at $90 \%$. Using Equation (7) and the $b=0.066$ growth factor for Golden Ears, particle growth factor at $90 \%$ relative humidity was calculated to be 1.18 . Bimodal distributions were more predominant for the $114 \mathrm{~nm}$ particles. Bimodal humidified distributions for $81 \mathrm{~nm}$ particles were observed largely on 11 August.

When the distributions were bimodal, growth factors for the less hygroscopic particles were higher than had been observed for monomodal distributions. The growth factors for the more 
hygroscopic particles were significantly larger and were similar to those observed at Eagle Ridge, a site significantly more impacted by anthropogenic sources. These findings suggest that bimodal distributions at Golden Ears were due to contributions from an anthropogenic source. The 11th of August, when bimodal distributions were noted for both sizes, was the Saturday of a busy weekend at the park. It was therefore possible that during this time there were significant local anthropogenic contributions to particles. Bimodal distributions on 7 August were different from those observed on 11 August in that they were only observed for the $114 \mathrm{~nm}$ particles, even though some measurements were performed at relative humidities as high as $89 \%$. Furthermore, the less hygroscopic fractions for 7 August were lower than those observed on 11 August. Since there was no observed increased activity within the park on 7 August, the change in the hygroscopicity of the particles during this time may have been due to a change in transport; this may have reduced the fetch over the forested area and/or brought to the site an air mass with higher anthropogenic influence. Unfortunately, meteorological data, with the exception of temperature and relative humidity, was not available for this site. Meteorological measurement made $8 \mathrm{~km}$ from the site indicated a diurnal pattern in wind direction. During nights and early mornings winds were from the north or the east, constituting a downslope flow from the mountains to the valley. During the day, winds were mainly from the west or southwest, indicating an upslope flow from the valley; this air mass would have been much more impacted by anthropogenic emissions. This pattern was not found to be different for the 7 August. On the other hand particle chemistry measurements showed a decrease in ammonium and sulphate ions after 7 August, while the organic component increased (Shantz, personal communication). The occasional, short-lived bimodal distributions observed at other times (8-10 August) may have been due to vehicular activity within the park ranger's compound. Growth factors for the more hygroscopic particles during this time ranged from 1.23 to 1.39 , measured at relative humidity of $80 \pm 3 \%$.

As noted above, the particle-to-particle variations in water sorption that resulted in bimodal distributions were observed when particles were humidified to a relative humidity equal to or greater than $75 \%$. Slight variations in water sorption were not enough to produce bimodal distributions, but were exhibited as an increase in the spread factor of a monomodal distribution. These slight variations in water sorption start to become apparent at about $60 \%$ relative humidity, well below the point where bimodal distributions were observed. Some of these monomodal distributions split into bimodal distributions at higher relative humidity, but, as was already discussed, bimodal distributions were not a common result at this site.

We describe the variations within a mode in terms of the spread factor, defined in Equation (3). Zero spread factor indicates no variation in water uptake; a spread factor was classified as being significant if its value was greater than $1.0 \%$; this level was chosen because it is three times the average sigma for spread factors measured below $60 \%$ relative humidity. Seventyeight percent of the distributions showed significant spread factors when the relative humidity was greater than $60 \%$. Therefore, although only a small fraction of the humidified distributions resulted in distinct bimodal distributions, the majority showed some level of external mixing. Higher spread factors only occurred when particles were humidified to high relative humidity; however, humidification to high relative humidity did not always result in higher spread factors.

Spread factors were found to correlate with growth factors. For measurements done at $80 \pm 1 \%$ relative humidity, correlation coefficients of 0.85 for $114 \mathrm{~nm}$ and 0.76 for $81 \mathrm{~nm}$ were found. A possible explanation for this is as follows. Assume that the particles are initially of low hygroscopicity and that a more soluble component is added to them. A larger growth factor implies a larger time for reaction, while a larger spread factor implies a larger variance in reaction time. Under fully mixed flow conditions, the reaction time is equal to its standard deviation (Wala 1997). So this correlation may be a result of these particles being processed under mixed flow conditions. A linear fit of spread factor versus growth factor for measurements carried out at $80 \%$ relative humidity yields

$$
G F=1.06+(D F \times 0.0125) .
$$

$G F$ is the growth factor, and the spread factor $(D F)$ is in percentage. When $D F=0$, the growth factor of 1.06 estimated by the above fit was within error of the values measured at $80 \%$ relative humidity.

\section{Eagle Ridge Mountain}

Meteorology at the Site. In the absence of strong synoptic forcing, the diurnal cycle of daytime sea breeze (westerly, inflow) and nighttime land breeze (easterly, outflow) characterized the flow pattern in the area. The lower Fraser Valley runs roughly east-west; the western section of the valley is the most populated. Inflow brought to the site air that was heavily influenced by anthropogenic activity; this type of flow, when present, usually occurred in the afternoon. Downslope flows (outflow) most likely contain biogenically influenced particles.

The first seven sample days at Eagle Ridge (14-20 August) were dry and sunny. Stagnant conditions and low daytime mixing heights (between $500-1000 \mathrm{~m}$ ) on 14 and 15 August resulted in smog events; visibility in the valley during these days was greatly reduced. Visibility started to improve on the 16 August. From the 16-20 August, the dominant flow was southeasterly (outflow), with a weak inflow in the afternoons. This, coupled with increasing mixing heights (to $2000 \mathrm{~m}$ on 20 August), resulted in relatively clean conditions. During this period, local wind directions at the site at night and in the early mornings were northerly; by the afternoon, the wind direction shifted to southwesterly. This was in agreement with the flow pattern observed in the valley. 
Widespread precipitation began on 21 August and continued through to 23 August. The heaviest precipitation was noted for 21 and 22 August; on the 23 August, intermittent showers prevailed during the day and heavy precipitation was noted during the evening. On 21 August and till 09:00 on 22 August wind direction was from the east. For the remainder of the rain period wind speed decreased and wind direction shifted to the southwest.

Following the wet period, many of the remaining sample days had a significant amount of cloud cover, but no rain was observed. Some reduction in visibility was observed during the end of the study, but due to the lack of strong blocking pattern, visibility was not reduced to the extent observed at the start of the study. During this period, daytime winds were light and variable; wind direction varied from northwest to southwest. Stronger winds $(>1.5 \mathrm{~m} / \mathrm{s})$ were noted at night and during the time the site was above the nocturnal boundary layer; wind direction during these times was from the east. Based on the meteorology at the site, the sample time was divided into four periods: Smog period (14 and 15 August), Prerain period (16-20 August), Rain period (21-23 August), and Postrain period (2431 August).

Measured Hygroscopic Properties. Particulates at Eagle Ridge were expected to be representative of processed air and to be influenced by both biogenic and anthropogenic processes. Notable differences in the growth curves were observed from one day to another. Humidified particles at this site either had a single mode or were composed of more and less hygroscopic modes. The average growth factors at $80 \%$ relative humidity were determined for each of the four sample periods; there was no significant difference between the sizes (Table 1). The less hygroscopic particles were found to be consistent with growth factor of about 1.09; this value is very similar to growth factors observed for Golden Ears forest particles. Growth factors for the more hygroscopic mode ranged from 1.23 to 1.34 and were similar to urban and semiurban particles measured by Ferron et al. (1999). The single mode showed the most variability; their growth factors ranged between the growth factors for the more and less hygroscopic modes. This suggests that there were two basic components and that the monomodal distributions were composed of varying contributions from these.

Figure 6 illustrates the hygroscopic behavior of $114 \mathrm{~nm}$ particles sampled before the rain event, between 14 and 20 August. A small amount of hygroscopic growth is observed between $60 \%$ and $70 \%$ relative humidity; above $70 \%$ relative humidity the more hygroscopic and monomodal particles showed a significant amount of growth, while the less hygroscopic group sorbed very little water. Figure 7 shows the growth curve for a rainy day. Particles on this day had a single mode and sorbed very little water; growth factors lie close to the fitted growth curve. Figures 6 and 7 also show fits to growth factors for the less hygroscopic particles. Note that the fitting parameter $b$, in Figures 6 and 7 has a similar value to those obtained at Golden Ears between 8 and 10 August. Thus the less hygroscopic particles, particles during the rain period, and particles at Golden Ears have very similar hygroscopic properties.

The humidified particles were most often monomodal, especially for the $50 \mathrm{~nm}$ particles. With a few exceptions, bimodal distributions were only observed for measurements at relative humidities greater than $75 \%$; they comprised $21 \%$ of those measurements. Seventyeight percent of the bimodal distributions were for $114 \mathrm{~nm}$ particles. For the bimodal distributions, growth factors for the less and more hygroscopic modes remained largely unchanged over the sample period. At $80 \%$ relative humidity, the more hygroscopic mode had a growth factor of about 1.28 and the less hygroscopic mode had a growth factor of about 1.09 .

Bimodal distributions for both sizes were most commonly observed between 10:00 and 12:00, coinciding with the arrival of the growing boundary layer at the site. This suggests that the external mixing was due to the mixing of air masses that were above and within the inversion layer. The mixing process typically produced a much greater influx of particles at $50 \mathrm{~nm}$ than at $114 \mathrm{~nm}$. This likely accounts for the less frequent observation of external mixing at $50 \mathrm{~nm}$; the large number of particles at that size from within the inversion layer would have swamped any contribution from the above the inversion layer. Bimodal distributions for $50 \mathrm{~nm}$ particles were observed when particle concentration below the boundary layers were comparable to that above.

Eighty eight percent of the monomodal distributions measured above $60 \%$ relative humidity showed significant spread factors. Values observed at Eagle Ridge were comparable to the anthropogenic influenced particles at Golden Ears (on August 7 and 11). The relationship between spread factors and growth factors for monomodal distributions at Eagle Ridge was such that lower spread factors were observed when growth factors were either at the high or low end of the values measured during the study. The maximum spread factors of $11 \%$ were observed when growth factors were about 1.17 . This finding adds support to the suggestion that the monomodal distributions were composed of two basic components with hygroscopic properties that were approximated by the two ends of the spectrum of hygroscopic values observed, 1.06 and 1.43 at $80 \%$ relative humidity. Note that at Golden Ears only a positive correlation was found as growth factors at that site rarely exceeded 1.17; otherwise, data at the two sites were very similar. For growth factors below 1.17 the relationship between spread and growth factor for particles at Eagle Ridge was

$$
G F=1.06+(D F \times 0.011)
$$

This is comparable to Equation (8), obtained for Golden Ears particles. This relationship between the spread factor and growth factor becomes evident following the smog event (15 August) and was most pronounced during and after the rain event. A more defined relationship was found for $114 \mathrm{~nm}$ particles than for the $50 \mathrm{~nm}$ particles. 
Estimating Organic Fraction. The observed variability in the hygroscopic properties of particles is most likely due to the varying fraction of organic compounds in the particles. The less hygroscopic mode was most probably largely composed of organic material. A higher inorganic fraction in the more hygroscopic mode and the single modes can explain their greater ability to sorb more water. Virkkula et al. (1999) have shown that the growth factor, $G F_{\text {mixed }}$, of a mixed particle can be estimated from the growth factor of its components by the equation

$$
G F_{\text {mixed }}^{3}=\left(G F_{\text {org }}^{3} \times \varepsilon_{\text {org }}\right)+\left(G F_{\text {inorg }}^{3} \times\left(1-\varepsilon_{\text {org }}\right)\right),
$$

where $\varepsilon_{\text {org }}$ is the organic fraction of the particle and $G F_{\text {org }}$ and $G F_{\text {inorg }}$ are the growth factors for pure organic and pure inorganic particles. We assume the inorganic fraction is a sulphate salt and that the hygroscopic behavior of the organic fraction is given by that for the less hygroscopic mode at Eagle Ridge, that is, by Equation (7) with $b=0.050$. The error introduced by neglecting the Kelvin effect when calculating $\mathrm{GF}_{\text {org }}$ results in overestimating the organic fraction by $2.6 \%$ at $85 \%$ relative humidity, assuming that the particle has the same surface tension as water. Smaller errors occur with lower relative humidity and smaller surface tension, as expected for organic particle; thus, we neglect the Kelvin effect when determining $\mathrm{GF}_{\text {org }}$.

In most cases, particles were observed to sorb a significant amount of water above $70 \%$ relative humidity (see Figure 6). This could have resulted from the presence of $\left(\mathrm{NH}_{4}\right)_{3} \mathrm{H}\left(\mathrm{SO}_{4}\right)_{2}$ (letovicite), which has a deliquescence relative humidity of 69\% (Tang and Munkelwitz 1994), compared to a deliquescent relative humidity of $80 \%$ for $\left(\mathrm{NH}_{4}\right)_{2} \mathrm{SO}_{4}$ (ammonium sulphate). However, laboratory experiments have shown the deliquescent point of $\left(\mathrm{NH}_{4}\right)_{2} \mathrm{SO}_{4}$ may be reduced in the presence of organic species (Brooks et al. 2003); so we cannot rule this out as the inorganic salt. The hygroscopic growth of the inorganic salt was calculated from

$$
G F_{\text {inorg }}=\left(\frac{\rho_{\text {dry }}}{w \rho_{s} \ln }\right)^{1 / 3}
$$

where $\rho_{d r y}$ is the density of the dry particle, $\rho_{s}$ in is the density of the solution, and $w$ is the solute weight percent. Solution density and composition for various water activities were calculated using equations given by Tang and Munkelwitz (1994). Organic fractions for particles were calculated for each mode, assuming the inorganic fraction to be either letovicite or ammonium sulphate. The average difference in these estimates of organic fraction was not significant ( $3 \%$ for $114 \mathrm{~nm}$ ); the results presented here are estimates made using letovicite. When there were two hygroscopic modes, the combined organic fraction, $\varepsilon_{\text {org_c }}$, was estimated using

$$
\varepsilon_{\text {org_C }}=\left(f_{1} \times \varepsilon_{\text {org_ } 1}\right)+\left(1-f_{1}\right),
$$

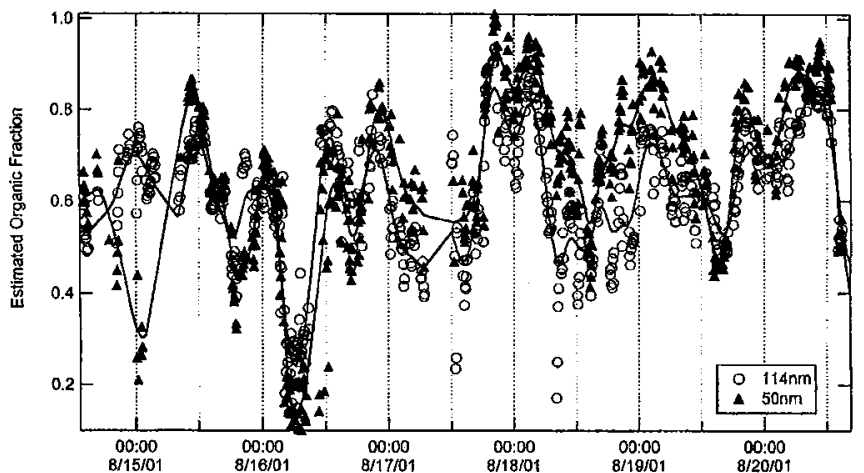

Figure 8. Estimated organic volume fraction for $50 \mathrm{~nm}$ and $114 \mathrm{~nm}$ particles during the smog and prerain periods. The solid line is a smoothing spline interpolation for $50 \mathrm{~nm}$ particles and the broken line is for $114 \mathrm{~nm}$ particles.

where $f_{1}$ is the fraction of particles in the more hygroscopic mode and $\varepsilon_{\text {org }}$ is the estimated organic fraction for the more hygroscopic mode. The results indicate that 50,114 , and $160 \mathrm{~nm}$ particles were overwhelmingly organic, with the even more hygroscopic particles usually consisting of more than $50 \%$ organic material. Figures 8,9 , and 10 show the estimated organic fraction before, during, and after the rain period. Because of the assumptions made in estimating the organic fractions, these numbers should be regarded as a qualitative guide to the relative amounts of organic and inorganic material rather than as a quantitative measure.

Diurnal variations in the estimated organic fraction were observed for both 50 and $114 \mathrm{~nm}$ particles between August 15 and 20; this is shown in Figure 8. During the smog event (14 and 15 August), a diurnal variation was evident only for the $50 \mathrm{~nm}$ particles; for these particles the organic fraction peaked in the

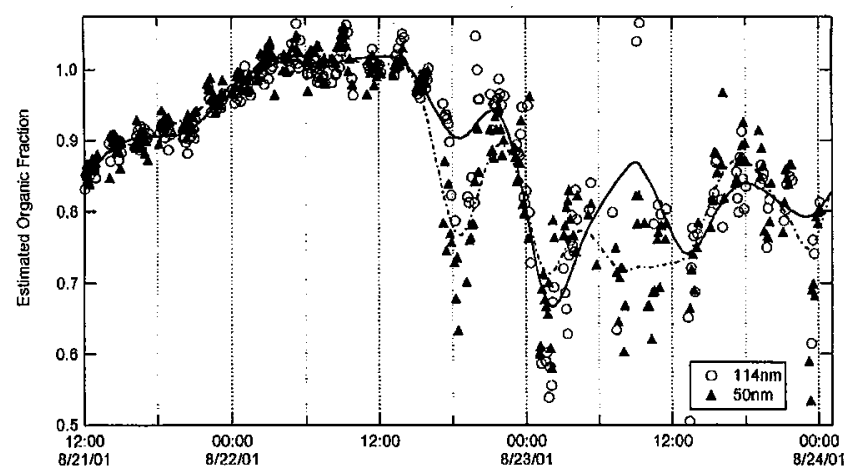

Figure 9. Estimated organic volume fraction for $50 \mathrm{~nm}$ and $114 \mathrm{~nm}$ particles during the wet period. Due to an equipment failure, no data was collected before 11:00 on 21 August. The solid line is a smoothing spline interpolation for $50 \mathrm{~nm}$ particles and the broken line is for $114 \mathrm{~nm}$ particles. 


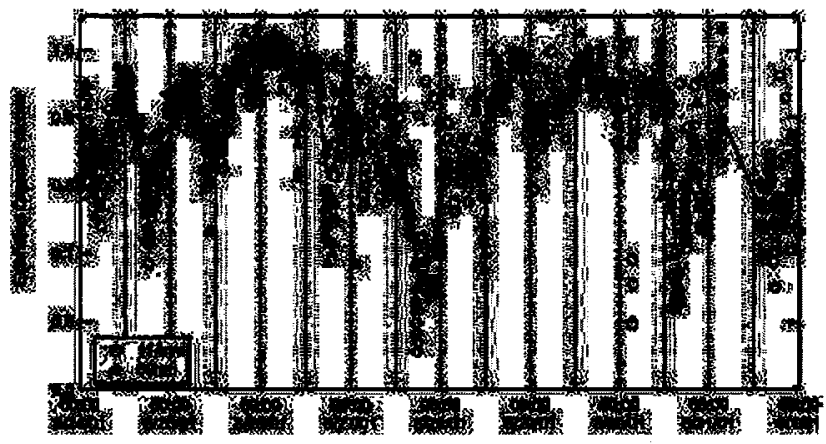

Figure 10. Estimated organic volume fraction for $50 \mathrm{~nm}$ and $114 \mathrm{~nm}$ particles during the postrain period. The line is a smoothing spline interpolation for $114 \mathrm{~nm}$ particles.

daytime. Continuous data were not available for the first sample day (14 August) of the smog event, but estimates of organic fraction from August 15 show that organic fractions were lower between midnight and 02:00, and higher between 10:00 and $12: 00$. In the days that followed the smog event, a diurnal variation was observed for both sizes, but it was more pronounced for the $50 \mathrm{~nm}$ particles. Between 16 and 20 August, minima in the organic fraction were observed at 14:00 with the exception of 16 August, when it was observed at 06:00. The maximum organic fraction usually occurred in the evening between 20:00 and 22:00. The night of 15 August and the early morning of 16 August mark the end of the stagnant conditions that had resulted in smog events. The increase in organic fraction in the evening of 15 August, followed by a dramatic decrease after midnight, may have marked this process.

Figure 8 shows that between 16 and 20 August the increases in the estimated organic fraction at both 50 and $114 \mathrm{~nm}$ were not observed until approximately four hours after boundary layer breakup at 14:00. This indicates that the process involved was photochemistry and that the boundary layer breakup did not affect the organic fraction. Between 16 and 20 August, once the organic fraction reached a maximum (between 20:00 and 22:00) it was shortly followed by a decrease. This may be due to the reduction in the amount of condensable organic material available as the nocturnal boundary layer forms, and/or it may be due to a change in air mass.

An examination of the particle size distributions revealed that at times particles were undergoing significant growth at this site. These growth events occurred around the time changes in particle hygroscopicity were observed. On 15 August the decrease in the organic fraction for $50 \mathrm{~nm}$ particles started after 12:00 and coincided with one of these growth events. This may have been due to gas-to-particle conversion of inorganic material.

Rain started early in the morning of 21 August and lasted into the morning of the 24 August; results for this period are shown in Figure 9. Two types of hygroscopic behavior were observed during this rain period. From 11:00 on 21 August until 15:00 on 22 August there was only a single hygroscopic mode. During this time, the organic fractions in both the 50 and $114 \mathrm{~nm}$ particles increased to very near unity. Selective wet deposition of hygroscopic particles cannot account for these observations since the $50 \mathrm{~nm}$ particles were probably too small to act as cloud condensation nuclei, while physical scavenging processes would not discriminate on the basis of particle composition. However, if the primary particles were organic, then the washing out of gases such as $\mathrm{SO}_{2}, \mathrm{HNO}_{3}$, and $\mathrm{NH}_{3}$ would prevent the addition of more hygroscopic material to the particles. During this time, the wind was from the east, so the primary particles may well have been biogenic organic particles, as observed at Golden Ears.

A second type of behavior was observed for the remainder of the rain period. As seen in Figure 9, at about 15:00 on 22 August the organic fraction for both 50 and $114 \mathrm{~nm}$ particles began to decrease. There were no prolonged stoppages or reduction in precipitation during this period, but after 12:00 on 22 August the general wind direction changed from easterly to southwesterly. Thus, the source of the primary particles may have shifted from biogenic to anthropogenic. The $50 \mathrm{~nm}$ particles showed bimodal hygroscopic behavior starting at the onset of the organic fraction decrease; bimodal hygroscopic behavior for the $114 \mathrm{~nm}$ particles was not observed until 03:00 on the 23 August. During the rainy period, a majority of the particles were in the less hygroscopic mode; this was atypical for Eagle Ridge.

During the postrain period (24-31 August), particles were generally more hygroscopic than during the rain period, but significantly less hygroscopic than during the prerain period. Due to low concentrations of $50 \mathrm{~nm}$ particles at night, sampling for this size was done only during the day from 27-31 August; at night, $160 \mathrm{~nm}$ particles were sampled instead. Figure 10 shows the estimated organic fractions during this period. Decrease in organic fractions were observed for short intervals on all days except 28 and 29 August. These decreases start between 10:00 and 13:00 and coincide with the observation of large concentrations of small particles $(<60 \mathrm{~nm})$. The decrease in organic fraction was most pronounced on 27,30, and 31 August. At these times, in addition to the large number of small-sized particles, a separate event of pronounced growth events involving much smaller particles $(<30 \mathrm{~nm})$ was observed. Thus, as on 15 August, gas-to-particle conversion appears to have made the particles more hygroscopic. The organic fractions reached minima at 18:00 and then increased. From midday on 28 August through 29 August the organic fraction was high and showed little variation. During these times neither large concentration of small particles nor growth events was observed.

\section{CONCLUSIONS}

We have developed a method for measuring particle growth factors over a range of relative humidities from $50 \%$ to $85 \%$. This 
system was deployed in the Lower Fraser Valley. The, results of these TDMA measurements were much simpler than might have been expected given the wide range of sources within the Fraser Valley. A consistent feature was the presence of particles of low hygroscopicity; these particles were probably of almost entirely organic composition. They showed remarkably uniform growth curves, with wet/dry diameter ratios that increased from 1.04 at $50 \%$ relative humidity to 1.09 at $80 \%$ relative humidity. At the forested site in Golden Ears Park and during part of the rainy period at Eagle Ridge, these particles constituted almost the entire aerosol, at least for the 50 and $114 \mathrm{~nm}$ diameter particles sampled.

At other times there was either a second, more hygroscopic mode or a single mode that was more hygroscopic than the organic particles. These hygroscopic particles showed pronounced growth at relative humidities above $70 \%$. However, the growth factors for these particles were much less than expected for pure inorganic salts such as $\left(\mathrm{NH}_{4}\right)_{2} \mathrm{SO}_{4}$ or $\left(\mathrm{NH}_{4}\right)_{3} \mathrm{H}\left(\mathrm{SO}_{4}\right)_{2}$. We therefore infer that these particles consisted of a mixture of organic and inorganic components. The humidified size distributions of these particles were usually very broad, indicating that they had a range of particle compositions. The least amount of spread was observed for the single mode particles measured at Golden Ears Forest. The separation between less and more hygroscopic particles was more distinct for $114 \mathrm{~nm}$ particles than for 50 $\mathrm{nm}$ particles. The $50 \mathrm{~nm}$ particles did, however, show increased spread factors when the $114 \mathrm{~nm}$ particles showed external mixing. When bimodal distributions were present, the less hygroscopic fraction was found to be larger at $50 \mathrm{~nm}$ than at $114 \mathrm{~nm}$. This was consistent throughout the study.

A relationship between spread factor and growth factor was found which showed a positive correlation for growth factors less than 1.17 and a negative correlation for growth factors greater than 1.17. The upper limit for the spread factor was about $11 \%$, observed for samples that had growth factors of about 1.17. This supports the assumption that particles at the site had two principal components whose hygroscopic behavior was approximated by the upper and lower hygroscopic limits (1.06 to 1.43$)$ observed during the study. The larger spread factor for particles with growth factor between these limits may have been due to varying fractions of the two components.

By using the observed growth factors for the pure organic particles and calculated growth factors for inorganic salts, we were able to estimate the relative organic and inorganic fractions in these particles. Diurnal variation, with higher organic fractions at night, was observed during the clean period. High organic fractions were also noted during the first segment of the rain period. These highly organic particles were likely of biogenic origin. During the postrain period and on the one smog event day, the lowest organic fractions coincided with particle growth events.

\section{REFERENCES}

Atkins, P. (1994). The Properties of Simple Mixtures: Partial Molar Properties. In Physical Chemistry, W. H. Freeman and Company, New York, pp. 208-213.

Brooks, S. D., Garland, R. M.,Wise, M. E., Prenni, A. J., Cushing, M., Hewitt, E., and Tolbert, M. A. (2003). Deliquescence and Efflorescence of Mixed Maleic Acid/Ammonium Sulfate Aerosols, Journal of Geophysical Research 108 (D15), Art No. 4487.

Cocker, D. R., Whitlock, N. E., and Flagan, R. C. (2001). Hygroscopic Properties of Pasadena, California Aerosol, Aerosol Sci. Technol. 35:637-647.

Cruz, C. N., and Pandis, S. N. (2000). Deliquescence and Hygroscopic Growth of Mixed Inorganic-Organic Atmospheric Aerosol, Environ. Sci. Technol. 34:4313-4319.

Derwitt, G. B., Curren, K., Steyn, D. G., Gillespie, T. J., and Niki, H. (1998). Measurement of Biogenic Hydrocarbon Emissions form Vegetation in the Lower Fraser Valley, British Colombia, Atmos. Environ. 32:3457-3466.

Dick, W. D., Saxena, P., and McMurry, P. H. (2000). Estimation of Water Uptake by Organic Compounds in Submicron Aerosols Measured During the Southeastern Aerosol and Visibility Study, J. Geophys. Res. 105:1471-1479.

Ferron, G. A., Karg, E., Busch, B., and Heyder, J. (1999). Hygroscopicity of Ambient Particles, J. Aerosol Sci. 30:S19-S20.

Ha, Z., Choy, L., and Chan, C. K. (2000). Study of Water Activities of Supersaturated Aerosols of Sodium and Ammonium Salts, J. Geophys. Res. 105(D6): 11,699-11,709.

Hämeri, K., Väkevä, M., Aalto, P. P., Kulmala, M., Swietlicki, E., Zhou, J., Seidl, 'W., Becker, E., and O'Dowd, D. (2001). Hygroscopic and CCN Properties of Aerosol Particles in Boreal Forests, Tellus 53B:359-379.

Jokinen, V., and Mäkelä, J. M. (1997). Closed-Loop Arrangement with Critical Orifice for DMA Sheath/Excess Flow System, J. Aerosol Sci. 28:643648.

Knutson, E. O, and Whitby, K. T. (1975). Anomalous Unipolar Diffusion Charging of Polystyrene Latex Aerosols, J. Colloid Interface Sci. 53:493-495.

McMurry, P. H., and Stolzenburg, M. R. (1989). On the Sensitivity of Particle Size to Relative Humidity for Los Angeles Aerosol, Atmos. Environ. 23:497507.

Peng, C., Chan, M. N., and Chan, C. K. (2001). The Hygroscopic Properties of Dicarboxylic and Multifunctional Acids: Measurements and UNIFAC Predictions, Environ. Sci. Technol. 35:4495-4501.

Pitchford, M. L., and McMurry, P. H. (1994). Relationship Between Measured Water Vapor Growth and Chemistry of the Atmospheric Aerosol for Grand Canyon, Arizona, in Winter 1990, Atmos. Environ. 28:827-839.

Stolzenburg, M. R., and McMurry, P. H. (1988). TDMAFIT User's Manual. Minneapolis, MN, Department of Mechanical Engineering, University of Minnesota.

Tang, I. N. (1997). Thermodynamic and Optical Properties of MixedSalt Aerosols of Atmospheric Importanice, J. Geophys. Res. 102:18831893.

Tang, I. N., and Munkelwitz, H. R. (1994). Water Activities, Densities and Refractive Indices of Aqueous Sulfates and Sodium Nitrate Droplets of Atmospheric Importance, J. Geophys. Res. 99:18801-18808.

Virkkula, A., Van Dingenen, R., Raes, F., and Hiorth, J. (1999). Hygroscopic Properties of Aerosol Formed by Oxidation of Limonen, a-pinene, and b-pinene, J. Geophys. Res. 104:3569-3579.

Wala, S. M. (1997). Chemical Reactors: Residence Time Distribution (RTD) and Reactor Efficiency. In Perry's Chemical Engineers' Handbook, edited by R. H. Perry, D. W.Green, and J. O. Maloney. McGraw-Hill, New York, pp. 23:15-25.

Wang, S. C., and Flagan, R. C. (1990). Scanning Electrical Mobility Spectrometer, Aerosol Sci. Technol. 13:230-240.

Zhou, J., Swietlicki, E., Hansson, H. C., and Artaxo, P. (1999). Aerosol Particle Size Distribution and Hygroscopic Growth in the Amazonian Rain Forest, J. Aerosol Sci. 30:S163-S164. 
APPENDIX: SUPPLEMENTARY INFORMATION

Table A1

Percentage spread factors

\begin{tabular}{|c|c|c|c|c|}
\hline \multirow[b]{2}{*}{ Sample period } & \multicolumn{4}{|c|}{ Particle dry diameter } \\
\hline & $50 \mathrm{~nm}$ & $81 \mathrm{~nm}$ & $114 \mathrm{~nm}$ & $160 \mathrm{~nm}$ \\
\hline \multicolumn{5}{|l|}{ Single hygroscopic mode } \\
\hline \multicolumn{5}{|l|}{ Golden Ears } \\
\hline 7 and 11 August ${ }^{a}$ & N/A & $3.7_{-1.9}^{+3.3}$ & $4.6_{-2.3}^{+2.7}$ & N/A \\
\hline 8 and 9 August & N/A & $2.1_{-2.7}^{+1.8}$ & $1.5_{-2.5}^{+1.3}$ & N/A \\
\hline 10 and 11 August $^{b}$ & N/A & $1.5_{-2.6}^{+1.1}$ & $1.5_{-2.6}^{+1.3}$ & N/A \\
\hline \multicolumn{5}{|l|}{ Eagle Ridge } \\
\hline 14 and 15 August & $3.2_{-2.1}^{+3.8}$ & N/A & $3.5_{-1.4}^{+2.7}$ & N/A \\
\hline 16-20 August & $4.1_{-2.4}^{+2.6}$ & N/A & $3.5_{-1.1}^{+2.9}$ & N/A \\
\hline 21-23 August & $3.3_{-1.8}^{+3.4}$ & N/A & $3.7_{-2.0}^{+\overline{3} . \overline{3}}$ & N/A \\
\hline 24-31 August & $3.1_{-17}^{+3.0}$ & N/A & $3.8_{-2.6}^{+3.0}$ & $4.0_{-2 .}^{+2.5}$ \\
\hline \multicolumn{5}{|l|}{ More hygroscopic mode } \\
\hline \multicolumn{5}{|l|}{ Golden Ears } \\
\hline 7-11 August & N/A & $4.0_{-1.1}^{+1.5}$ & $3.8_{-1.9}^{+4.9}$ & N/A \\
\hline \multicolumn{5}{|l|}{ Eagle Ridge } \\
\hline 14 and 15 August & $1.7_{-3.2}^{+1.9}$ & N/A & $2.5_{-3.9}^{+1.6}$ & N/A \\
\hline 16-20 August & $4.1_{-2.8}^{+2.2}$ & N/A & $3.0_{-1.6}^{+2.5}$ & N/A \\
\hline 21-23 August & $3.6_{-2.1}^{+4.1}$ & N/A & $3.5_{-2.2}^{+3.2}$ & N/A \\
\hline 24-31 August & $2.6_{-1.5}^{+5.6}$ & N/A & $2.9_{-1.7}^{+1.8}$ & $2.6_{-2.5}^{+1.9}$ \\
\hline \multicolumn{5}{|l|}{ Less hygroscopic mode } \\
\hline \multicolumn{5}{|l|}{ Golden Ears } \\
\hline 7-11 August & N/A & $3.3_{-3.0}^{+3.2}$ & $3.2_{-1.7}^{+4.2}$ & N/A \\
\hline \multicolumn{5}{|l|}{ Eagle Ridge } \\
\hline 14 and 15 August & $6.8_{-4.2}^{+2.0}$ & N/A & $5.8_{-3.3}^{+3.6}$ & N/A \\
\hline 16-20 August & $3.3_{-3.8}^{+6.3}$ & N/A & $4.1_{-3.0}^{+3.6}$ & N/A \\
\hline 21-23 August & $2.9_{-1.7}^{+3.4}$ & N/A & $3.8_{-1.9}^{+2.4}$ & N/A \\
\hline 24-31 August & $2.8_{-1.7}^{-3.2}$ & N/A & $4.5_{-5.8}^{+4.4}$ & $4.5_{-4.4}^{+4.2}$ \\
\hline
\end{tabular}

${ }^{a} 11$ August 9:30-12:00.

${ }^{b} 11$ August midnight-9:30 p.m.

The subscript and superscript values indicate the 10th and 90th percentile limits, respectively. Spread factors are for all measurements done above $60 \%$ relative humidity, the relative humidity above which spread in diameter was significant.
Table A2

Less hygroscopic fraction

\begin{tabular}{lcccc}
\hline & \multicolumn{4}{c}{ Particle dry diameter } \\
\cline { 2 - 5 } Sample period & $50 \mathrm{~nm}$ & $81 \mathrm{~nm}$ & $114 \mathrm{~nm}$ & $160 \mathrm{~nm}$ \\
\hline Golden Ears & & & & \\
7 August & N/A & N/A & $0.49_{-0.27}^{+0.29}$ & N/A \\
11 August & N/A & $0.70_{-0.28}^{+0.17}$ & $0.71_{-0.05}^{+0.07}$ & N/A \\
Eagle Ridge & & & & \\
14 and 15 August & $0.50_{-0.16}^{+0.17}$ & N/A & $0.41_{-0.15}^{+0.13}$ & N/A \\
16-20 August & $0.37_{-0.15}^{+0.20}$ & N/A & $0.36_{-0.17}^{+0.17}$ & N/A \\
21-23 August & $0.58_{-0.14}^{+0.14}$ & N/A & $0.54_{-0.15}^{+0.09}$ & N/A \\
24-31 August & $0.52_{-0.22}^{+0.21}$ & N/A & $0.37_{-0.20}^{+0.25}$ & $0.32_{-0.14}^{+0.21}$ \\
\hline
\end{tabular}

Full-sized values are the median; the superscripted values are the 90 th percentile limits and the subscripted values are the 10th percentile limits. Less hygroscopic fraction is the ratio of number of particles within the less hygroscopic mode to the total number, when two modes are observed. These values are for all data points that contained two hygroscopic modes.

Table A3

Percentage of data with bimodal distribution

\begin{tabular}{lrrrr}
\hline & \multicolumn{4}{c}{ Particle dry diameter } \\
\cline { 2 - 5 } \multicolumn{1}{c}{ Sample period } & $50 \mathrm{~nm}$ & $81 \mathrm{~nm}$ & $114 \mathrm{~nm}$ & $160 \mathrm{~nm}$ \\
\hline Golden Ears & & & & \\
7 August & N/A & $2 \%$ & $30 \%$ & N/A \\
8-11 August & N/A & $0 \%$ & $1 \%$ & N/A \\
11 August & $41 \%$ & $60 \%$ & N/A & N/A \\
Eagle Ridge & & & & \\
14 and 15 August & $6 \%$ & N/A & $25 \%$ & N/A \\
16-20 August & $10 \%$ & N/A & $32 \%$ & N/A \\
21-23 August & $23 \%$ & N/A & $17 \%$ & N/A \\
24-31 August & $7 \%$ & N/A & $18 \%$ & $36 \%$ \\
\hline
\end{tabular}

${ }^{a} 11$ August midnight-9:30 p.m.

"11 August 9:30-12:00.

Values in the table were calculated using number of bimodal distributions observed and total number of data points above $75 \%$ relative humidity. Seventy five percent was chosen because it was above this relative humidity that bimodal distributions were observed. 
Table A4

Estimated organic volume fraction

\begin{tabular}{ccccc}
\hline & \multicolumn{4}{c}{ Particle dry diameter } \\
\cline { 2 - 5 } Sample period & $50 \mathrm{~nm}$ & $81 \mathrm{~nm}$ & $114 \mathrm{~nm}$ & $160 \mathrm{~nm}$ \\
\hline Single hygroscopic mode & & & & \\
Golden Ears & & & & \\
7-11 August & N/A & $1.01_{-0.07}^{+0.01}$ & $1.01_{-0.02}^{+0.01}$ & N/A \\
Eagle Ridge & & & & \\
14 and 15 August & $0.62_{-0.22}^{+0.20}$ & N/A & $0.62_{-0.13}^{+0.10}$ & N/A \\
16-20 August & $0.70_{-0.30}^{+0.20}$ & N/A & $0.56_{-0.25}^{+0.23}$ & N/A \\
21-23 August & $0.93_{-0.15}^{+0.09}$ & N/A & $0.95_{-0.14}^{+0.07}$ & N/A \\
24-31 August & $0.93_{-0.16}^{+0.06}$ & N/A & $0.91_{-0.15}^{+0.07}$ & $0.92_{-0.25}^{+0.05}$ \\
More hygroscopic mode & & & & \\
Golden Ears & & & & \\
7-11 August & N/A & $0.61_{-0.13}^{+0.09}$ & $0.61_{-0.04}^{+0.12}$ & N/A \\
Eagle Ridge & & & & \\
14 and 15 August & $0.56_{-0.13}^{+0.04}$ & N/A & $0.54_{-0.23}^{+0.13}$ & N/A \\
16-20 August & $0.43_{-0.21}^{+0.21}$ & N/A & $0.56_{-0.14}^{+0.12}$ & N/A \\
21-23 August & $0.47_{-0.12}^{+0.13}$ & N/A & $0.59_{-0.16}^{+0.08}$ & N/A \\
24-31 August & $0.60_{-0.11}^{+0.19}$ & N/A & $0.71_{-0.07}^{+0.07}$ & $0.62_{-0.07}^{+0.21}$ \\
Less hygroscopic mode & & & & \\
Golden Ears & & & & \\
7-11 August & N/A & $0.93_{-0.05}^{+0.03}$ & $0.96_{-0.08}^{+0.05}$ & N/A \\
Eagle Ridge & & & \\
14 and 15 August & $0.86_{-0.11}^{+0.15}$ & N/A & $0.91_{-0.18}^{+0.07}$ & N/A \\
16-20 August & $1.02_{-0.18}^{+0.05}$ & N/A & $0.99_{-0.17}^{+0.04}$ & N/A \\
21-23 August & $0.98_{-0.08}^{+0.05}$ & N/A & $0.94_{-0.08}^{+0.10}$ & N/A \\
24-31 August & $0.99_{-0.08}^{+0.07}$ & N/A & $0.99_{-0.11}^{+0.07}$ & $0.01_{-0.10}^{+0.06}$ \\
\hline
\end{tabular}

The table shows median, 10th, and 90th percentile; the subscripted values are the 10th percentile and the superscripted values are the 90 th percentile. 